\title{
Intramitochondrial Src kinase links mitochondrial dysfunctions and aggressiveness of breast cancer cells
}

\author{
Marie-Ange Djeungoue-Petga ${ }^{1,2}$, Olivier Lurette ${ }^{1,2}$, Stéphanie Jean ${ }^{1,2}$, Geneviève Hamel-Côté ${ }^{1,2}$, \\ Rebeca Martín-Jiménez ${ }^{1,2}$, Marine Bou ${ }^{1,2}$, Astrid Cannich ${ }^{3,4}$, Patrick Roy ${ }^{5}$ and Etienne Hebert-Chatelain ${ }^{1,2}$
}

\begin{abstract}
High levels and activity of Src kinase are common among breast cancer subtypes, and several inhibitors of the kinase are currently tested in clinical trials. Alterations in mitochondrial activity is also observed among the different types of breast cancer. Src kinase is localized in several subcellular compartments, including mitochondria where it targets several proteins to modulate the activity of the organelle. Although the subcellular localization of other oncogenes modulates the potency of known treatments, nothing is known about the specific role of intra-mitochondrial Src ( $\mathrm{mtSrc}$ ) in breast cancer. The aim of this work was to determine whether mtSrc kinase has specific impact on breast cancer cells. We first observed that activity of $\mathrm{mtSrc}$ is higher in breast cancer cells of the triple negative subtype. Overexpression of Src specifically targeted to mitochondria reduced mtDNA levels, mitochondrial membrane potential and cellular respiration. These alterations of mitochondrial functions led to lower cellular viability, shorter cell cycle and increased invasive capacity. Proteomic analyses revealed that $\mathrm{mtSrc}$ targets the mitochondrial single-stranded DNAbinding protein, a regulator of mtDNA replication. Our findings suggest that $\mathrm{mtS} r \mathrm{c}$ promotes aggressiveness of breast cancer cells via phosphorylation of mitochondrial single-stranded DNA-binding protein leading to reduced mtDNA levels and mitochondrial activity. This study highlights the importance of considering the subcellular localization of Src kinase in the development of potent therapy for breast cancer.
\end{abstract}

\section{Introduction}

Breast cancer $(\mathrm{BC})$ is characterized by various phenotype, clinical outcome, and response to treatment. $\mathrm{BC}$ can be classified into different subtypes based on the expression of the estrogen receptor (ER), progesterone receptor (PR) and the epidermal growth factor receptor 2 (HER2) ${ }^{1}$. For instance, ER and/or PR receptor-positive tumors are treated with endocrine therapy whereas aggressive HER2positive diseases are candidates for trastuzumab, a monoclonal antibody against $\mathrm{HER} 2^{2,3}$. In $15 \%$ of breast

\footnotetext{
Correspondence: Etienne Hebert-Chatelain (etienne.hebert.

chatelain@umoncton.ca)

${ }^{1}$ Canada Research Chair in Mitochondrial Signaling and Physiopathology, Moncton, NB, Canada

${ }^{2}$ Department of Biology, Université de Moncton, Moncton, NB, Canada

Full list of author information is available at the end of the article.

Edited by M. Campanella
}

tumors, none of these receptors are amplified. These socalled triple negative (TN) breast cancer are thus not responsive to trastuzumab or endocrine therapy and have a poor prognosis ${ }^{2,3}$. Several attempts were made to better characterize the molecular processes linked to heterogenous $\mathrm{BC}$ and generate potent and specific treatment to non-responding $\mathrm{BC}$.

Considering the role of metabolic pathways in cancer pathophysiology, numerous mitochondria-targeted strategies were developed for the treatment of cancer, including BC. Several cancer cells exhibit lower oxygen consumption and higher glycolysis activity ${ }^{4,5}$ and mitochondria are crucial components in this metabolic signature. These organelles play key functions in cell physiology, including generation of ATP, reactive oxygen species (ROS), apoptosis and calcium homeostasis. Their

\section{(c) The Author(s) 2019}

(c) (i) Open Access This article is licensed under a Creative Commons Attribution 4.0 International License, which permits use, sharing, adaptation, distribution and reproduction cc) in any medium or format, as long as you give appropriate credit to the original author(s) and the source, provide a link to the Creative Commons license, and indicate if changes were made. The images or other third party material in this article are included in the article's Creative Commons license, unless indicated otherwise in a credit line to the material. If material is not included in the article's Creative Commons license and your intended use is not permitted by statutory regulation or exceeds the permitted use, you will need to obtain permission directly from the copyright holder. To view a copy of this license, visit http://creativecommons.org/licenses/by/4.0/. 
functions are however readjusted in several types of cancer to sustain unlimited cell growth and proliferation, inhibition of apoptosis and intense anabolism ${ }^{5}$. Mitochondria appears metabolically dysfunctional in several cancer types, such as $\mathrm{BC}^{6,7}$. OXPHOS and ATP levels are decreased in breast cancer cells as compared to normal breast epithelial cells ${ }^{6}$. Altered oxidative phosphorylation (OXPHOS) can lead to upregulation of ROS levels and contribute to malignant transformation via the accumulation of oncogenic DNA mutations and activation of oncogenic signaling pathways ${ }^{8}$. The rewiring of mitochondrial metabolism also support high proliferation rates of various cancer cells. Several tricarboxylic (TCA) cycle intermediates, including alpha-ketoglutarate and citrate, are exported out of mitochondria to be used for biosynthesis of lipids, amino acids and nucleotides in cancer cells ${ }^{9}$. The metabolic phenotype is however variable among subtypes of $\mathrm{BC}$ cells. Triple negative $\mathrm{BC}$ (TNBC) cells have lower mitochondrial activity and higher glycolysis than other subtypes ${ }^{7}$. TNBC cells MDAMB-231 and MDA-MB-436 have a more fragmented mitochondrial reticulum, leading to increased migration and invasion capacities than the ER- and PR-positive MCF7 cells ${ }^{10}$. The glutaminase inhibitor CB-839 decreases proliferation of HCC-1806 and MDA-MB-231 TNBC cells without affecting ER-positive T47D cells ${ }^{11}$. These findings suggest that differential metabolic signatures of $\mathrm{BC}$ subtypes should be considered as potential therapeutic targets.

The c-Src kinase (named hereafter Src) oncogene is a well-known therapeutic target for various type of cancer including BC. Src is a central messenger in several important signaling pathways involved in proliferation, differentiation, survival, motility, and angiogenesis ${ }^{12,13}$. High expression and/or activity of Src is observed in several types of solid tumors, including BC tissue, where it is associated to increased invasiveness and metastatic potential, and with lower survival of patients ${ }^{14-16}$. Conversely, genetic or pharmacological disruption of Src activity decreases survival, migration, invasion and proliferation in $\mathrm{BC}$ cells ${ }^{17-21}$. Hence, several inhibitors of Src were developed and tested for the treatment of cancer and tumors $^{22-24}$. The impact of Src dysregulation appears however different among subtypes of breast cancer cells. For instance, the Src inhibitor dasatinib decreases the growth of TNBC cells without clear effect on other subtypes ${ }^{19,20}$. This different responsiveness of breast cancer sub-groups to therapies requires a better comprehension of the molecular machinery associated with the tumorigenic phenotype of breast cancer cells. Src is localized in multiple subcellular compartments, including nucleus, plasma membrane and mitochondria ${ }^{12,25-27}$. Interestingly, intra-mitochondrial $\mathrm{Src}(\mathrm{mtSrc})$ is present in different types of cancer cell, including $\mathrm{BC}$ cells ${ }^{26,27}$. The $\mathrm{mtSrc}$ targets various proteins involved in different mitochondrial functions, ranging from generation of ATP, production of ROS to apoptosis ${ }^{25,26,28-30}$. Although Src and mitochondria are both important in the pathophysiology of $\mathrm{BC}$, the role of $\mathrm{mtSrc}$ among $\mathrm{BC}$ subtypes remains scantly studied.

The aim of this work was to describe the role of $\mathrm{mtSrc}$ in metabolic and neoplasic phenotype of BC cells. To address this, we first characterized (mt)Src levels and activity in 12 control and $\mathrm{BC}$ cell lines. Our results show that mtSrc activity is highest in TNBC cells. To determine the precise role of $\mathrm{mtSrc}$, we expressed a mitochondria-targeted mutant of Src in several BC cells. Our findings demonstrate that over-expression of Src only in mitochondria is sufficient to alter mitochondrial metabolism, viability, proliferation and invasive capacities. This study also demonstrates that $\mathrm{mtSrc}$ induces mitochondrial dysfunctions and aggressiveness via phosphorylation of mitochondrial single-stranded DNAbinding protein and reduced mtDNA levels. Globally, this work provides a mechanistic explanation of why TNBC cells are more sensitive to Src inhibitors and suggests that targeting mtSrc signaling should be considered in the treatment of $\mathrm{BC}$.

\section{Methods \\ Material}

BT-483, SK-BR-3, MDA-MB-453, BT-549, hTERTHME-1, MDA-MB-468, and HCC-1954 cell lines were obtained from American Type Culture Collection (VA, USA). MDA-MB-231, MCF-7, T-47D, MCF-10A and MCF-12A cell lines were generously provided by the Atlantic Cancer Research Institute (Moncton, NB, Canada). Epidermal growth factor (EGF), bovine serum albumin (BSA) and actinomycin D (ACT001.5) were obtained from Bioshop (ON, Canada). Mouse monoclonal antibodies specific for HA-Tag (2367), phosphotyrosine (94115), $\alpha$-tubulin (3873), and rabbit monoclonal antibodies specific for Src (2123), phospho-Src Family Tyr-419 (6943), EGFR (4267), SOD2 (13141) were purchased from Cell signaling (USA). Mouse monoclonal antibodies specific for COXII (156031), UQCRC2 (14745), NDUFA9 (14713), ATP5A (110273), cytochrome c (110325) and SDHa (14715) were obtained from Abcam (Cambridge, UK). Mouse monoclonal antibody Src-B12 (8056) and rabbit polyclonal specific for TOM20 (11415) were purchased from Santa Cruz Biotechnology (Dallas, TX, USA). The horseradish peroxidase-conjugated $\mathrm{F}\left(\mathrm{ab}^{\prime}\right)_{2}$ fragment of anti-mouse (115-035-003) and anti-rabbit (111-035-003) were purchased from Jackson ImmunoResearch Laboratories (West Grove, PA, USA). Oligomycin (O4876), rotenone (R8875), antimycine A (A8674) and carbonylcyanide- $p$ fluoromethoxyphenylhydrazone (FCCP, C2920) were 
purchased from Sigma (MO, USA). Annexin V-FITC (640906) was purchased from Biolegend (CA, USA) and propidium iodide (PI, 40017) from Biotium Inc. (CA, USA). KI-67-FITC was purchased from Thermo Fisher Scientific (MA, USA).

\section{Cell culture}

MCF-10A and MCF-12A cells were maintained in culture with high glucose $(4.5 \mathrm{~g} / \mathrm{L})$ Dulbecco's modified Eagle's medium (DMEM) and Ham's F12 medium, respectively, supplemented with $20 \mathrm{ng} / \mathrm{mL}$ human epidermal growth factor, $100 \mathrm{ng} / \mathrm{mL}$ cholera toxin, $10 \mu \mathrm{g} / \mathrm{mL}$ bovine insulin, $500 \mathrm{ng} / \mathrm{mL}$ hydrocortisone, $500 \mathrm{ng} / \mathrm{mL}$ hydrocortisone, $2 \mathrm{mM}$ glutamine, $1 \mathrm{mM}$ pyruvate, $10 \%(\mathrm{v} /$ v) FBS, 100 units $/ \mathrm{mL}$ penicillin and $100 \mu \mathrm{g} / \mathrm{mL}$ streptomycin. BT-483 cells were maintained in RPMI-1640 supplemented with $2 \mathrm{mM}$ glutamine, $1 \mathrm{mM}$ pyruvate, $10 \%(\mathrm{v} / \mathrm{v})$ of FBS and penicillin-streptomycin. Other cell lines were maintained in culture with high glucose $(4.5 \mathrm{~g} /$ L) DMEM supplemented with $2 \mathrm{mM}$ glutamine, $1 \mathrm{mM}$ pyruvate, $10 \%(\mathrm{v} / \mathrm{v})$ of FBS and penicillin-streptomycin. MDA-MB-231 and BT-549 cells were also maintained in culture with DMEM without glucose supplemented with $2 \mathrm{mM}$ glutamine, $10 \mathrm{mM}$ galactose, $1 \mathrm{mM}$ pyruvate, $10 \%$ $(\mathrm{v} / \mathrm{v})$ of FBS and penicillin-streptomycin. All cell lines were kept at $37^{\circ} \mathrm{C}$ in $5 \% \mathrm{CO}_{2}$ and $95 \%$ humidity. Cells were maintained in their respective medium for at least five passages before analysis and the medium was renewed every 2 to 3 days. Analysis and cell harvesting were always performed when confluency was about $80-90 \%$.

\section{Plasmids}

To generate Src-HA and MLS-Src-HA constructs, the sequence of $\mathrm{Src}$ was amplified from pCMV5-Src (Addgene 13663) and fused to the sequence of human influenza hemagglutin (HA) and the mitochondrial leading sequence of cytochrome c oxidase subunit VIIIa. The Src-GFP mutant was kindly provided by Yoav Henis ${ }^{31}$ (Tel Aviv University, Israel). The phospho-deficient mutant mtSBB-Y73F was generated by PCR amplification of pCMV6-Entry-mtSBP from OriGene (MD, USA) using $5^{\prime}$-GGGGATAGTGAAGTTTTCCAACTGGG-3' and $5^{\prime}$-CTCCAGCTTGGTTCCCAATAGACC-3' primers. Plasmids were transfected using polyethylenimine (PolySciences, PA, USA). Cells were analyzed $48 \mathrm{~h}$ following transfection.

\section{Isolation of mitochondria}

Mitochondrial fractions were isolated as described previously ${ }^{32}$. Briefly, cells were harvested, resuspended in isolation buffer (250 mM sucrose, $1 \mathrm{mM}$ EDTA, $5 \mathrm{mM}$ HEPES, $\mathrm{pH}$ 7.4) containing protease and phosphatase inhibitor cocktails and disrupted with 15 strokes using a 25-gauge syringe. The cell debris and nuclei were removed by centrifugation at $1,500 \mathrm{~g}$ for $5 \mathrm{~min}\left(4^{\circ} \mathrm{C}\right)$. The supernatant was considered as total cell lysate (TCL) and was centrifuged at $12,500 \mathrm{~g}$ for $10 \mathrm{~min}\left(4^{\circ} \mathrm{C}\right)$. Then, the obtained supernatant was kept and considered as the cytosolic fraction (Cyto) whereas the pellet was resuspended. The centrifugation cycle was repeated and mitochondria-enriched fractions (Mito) were obtained from the last pellet.

\section{Gel electrophoresis and Western Blot}

Samples were diluted in SDS-PAGE sample buffer (62.5 mM Tris $1 \mathrm{M}, \mathrm{pH} 6.8 ; 10 \%(\mathrm{v} / \mathrm{v})$ glycerol, $2 \%(\mathrm{w} / \mathrm{v})$ sodium dodecylsulfate (SDS), $0.5 \%$ Bromophenol blue, $2.5 \%(\mathrm{v} / \mathrm{v}) \beta$-mercapto-ethanol) and boiled at $95^{\circ} \mathrm{C}$ during $5 \mathrm{~min}$. Samples were then separated using 7, 10 or $12 \%$ SDS-polyacrylamide mini-gel at $300 \mathrm{~V}$ during $30 \mathrm{~min}$. Proteins were blotted to polyvinylidine difluoride (PVDF) membranes. Membranes were blocked for $1 \mathrm{~h}$ in TBST containing 5\% BSA, and incubated with various primary antibodies. Lastly, membranes were incubated for $1 \mathrm{~h}$ with horseradish peroxidase-conjugated $\mathrm{F}\left(\mathrm{ab}^{\prime}\right)_{2}$ fragment of anti-mouse or anti-rabbit. Immunoblots were visualized by chemiluminescence using the ChemiDoc Touch imaging system (Biorad, CA, USA). Immunolabelings were quantified by densitometric analysis using Image $(\mathrm{NIH}$, MD, USA).

\section{Confocal microscopy}

Cells seeded on 18-mm round glass coverslips transfected and treated as indicated were placed on the stage of the Olympus FV1000 confocal fluorescence microscope (Tokyo, Japan) and imaged using a 60X oil objective (UPLAN 60x oil, 1.35NA, Olympus), and appropriate excitation laser and filters. For each experiment, 50 cells were randomly selected and analyzed. Stacks of 30 images separated by $0.2 \mu \mathrm{m}$ along the $\mathrm{z}$ axis were acquired. Three-dimensional reconstruction and volume rendering of the stacks were carried out with the appropriate plug-in of ImageJ (NIH).

\section{Oxygraphic measurements}

Oxygen consumption assays were performed using the high-resolution respirometry system Oxygraph-2k Oroboros (Innsbruck, Austria). Cell respiration was measured with $4 \times 10^{5}$ cells ml $^{-1}$ according to volume-specific flux at $37^{\circ} \mathrm{C}$ in $2 \mathrm{~mL}$ chambers at a stirring rate of $750 \mathrm{rpm}$. Three different states of endogenous respiration with intact cells were measured: (i) basal respiration representing the endogenous physiological coupled state, (ii) respiration with oligomycin $\left(2 \mu \mathrm{g} \mathrm{mL}^{-1}\right)$ representing the non-coupled resting respiration, and (iii) maximal uncoupled respiration induced by FCCP $(0.5 \mu \mathrm{M}$ steps with $2.5 \mu \mathrm{M}$ final concentration) providing a measure of the maximal capacity of ETS under conditions of physiological substrate supply in the intact cells. 


\section{Mitochondrial membrane potential, ROS production and mitochondrial mass}

Mitochondrial membrane potential was examined using tetramethylrhodamin, methyl ester (TMRM, LifeTechnologies, CA, USA). Briefly, cells were rinsed with PBS and incubated with $10 \mathrm{nM}$ TMRM during $15 \mathrm{~min}$ at $37^{\circ} \mathrm{C}$ in $5 \% \mathrm{CO}_{2}$ and $95 \%$ humidity. For all experiments, we confirmed that TMRM fluorescence was completely abolished following co-incubation with the mitochondrial uncoupler FCCP $(1.5 \mu \mathrm{M})$ (data not shown).

Oxidative stress was evaluated using MitoSox ${ }^{\mathrm{TM}}$ (Life Technologies, CA, USA). Briefly, cells expressing the different constructs were pre-incubated with vehicle or $0.5 \mu \mathrm{M}$ rotenone and $2.5 \mu \mathrm{M}$ antimycin A during $30 \mathrm{~min}$ at $37{ }^{\circ} \mathrm{C}$ in $5 \% \mathrm{CO}_{2}$ and $95 \%$ humidity. Upon treatment, cells were rinsed by PBS and incubated with $5 \mu \mathrm{M}$ MitoSox ${ }^{\mathrm{TM}}$ during $45 \mathrm{~min}$ at $37^{\circ} \mathrm{C}$ in $5 \% \mathrm{CO}_{2}$ and $95 \%$ humidity.

Mitochondrial mass was evaluated using Mitotracker Green $^{\mathrm{TM}}$ (Life Technologies, CA, USA). Briefly, cells were incubated with $150 \mathrm{nM}$ Mitotracker Green $^{\mathrm{TM}}$ during $30 \mathrm{~min}$ at $37^{\circ} \mathrm{C}$ in $5 \% \mathrm{CO}_{2}$ and $95 \%$ humidity.

After incubation with probes, cells were rinsed and imaging was performed. TMRM, MitoSox ${ }^{\mathrm{TM}}$ and Mitotracker Green $^{\mathrm{TM}}$ fluorescence were examined using the EVOS FL Auto 2 imaging system (Thermo Fisher Scientific, MA, USA) with a $\times 40$ objective (LPLAN $40 \times$, 0.65NA, EVOS). For each independent experiment, total fluorescence intensity was quantified for 50 cells using Image (NIH, MD, USA).

\section{ATP production}

The intracellular ATP production assay was assessed using the ATP bioluminescence assay kit HS II from Sigma (MO, USA) as described previously ${ }^{33}$. Briefly, $1 \times$ $10^{6}$ of cells were harvested in $1 \mathrm{~mL}$ DMEM medium. Cells were treated with vehicle or rotenone $(5 \mu \mathrm{M})$ and antimycin $\mathrm{A}(2.5 \mu \mathrm{M})$ during $1 \mathrm{~h}$ at $37^{\circ} \mathrm{C}$ under stirring. Then, cells were lysed using a boiling lysis buffer provided with the kit during $5 \mathrm{~min}$. Light emitted was detected and quantified using the Varioskan plate reader (Flash version 2.4.5, Thermo Fisher, MA, USA). The ATP content derived from mitochondria was determined by subtracting ATP levels obtained in cells treated with rotenone and antimycin A from the ATP levels obtained in untreated cells $($ ATPmito $=$ ATPtotal - ATProtenone + antimycin A).

\section{Immunoprecipitation}

The phosphorylation status of the cytochrome c oxidase subunit II (COXII) was examined using immunoprecipitation. Briefly, cells were harvested and resuspended in a non-denaturing lysis buffer $(20 \mathrm{mM}$ Tris $\mathrm{HCl} \mathrm{pH} 8$, $137 \mathrm{mM} \mathrm{NaCl}, 10 \%$ glycerol, $1 \%$ Triton X-100, $2 \mathrm{mM}$
EDTA) in the presence of $1 \%$ protease inhibitor cocktail (PIC002) (Bioshop, ON, Canada) and $2 \mathrm{mM}$ sodium orthovanadate. Following lysis, samples were centrifuged at $12,500 \mathrm{~g}$ during $10 \mathrm{~min}\left(4^{\circ} \mathrm{C}\right)$ to remove debris. Immunoprecipitation was performed on $2 \mathrm{mg}$ of protein with the antibody COXII overnight at $4{ }^{\circ} \mathrm{C}$. Protein A/G agarose beads $(20 \mu \mathrm{L}$, Santa Cruz, sc-2003) were then added and incubation continued during $4 \mathrm{~h}$ at $4{ }^{\circ} \mathrm{C}$ under continuous agitation. Beads were washed three times with non-denaturing lysis buffer and elution was performed with SDS-PAGE sample buffer during $5 \mathrm{~min}$ at $95^{\circ} \mathrm{C}$. Samples were then processed for western blotting.

\section{Apoptosis assays}

Apoptosis was measured in cells labeled with Annexin V-FITC and PI using flow cytometry. Briefly, cells were incubated with vehicle or actinomycin $\mathrm{D}(5 \mu \mathrm{M})$ during $48 \mathrm{~h}$. Cells were then harvested and resuspended in Annexin V binding buffer (Biolegend, 422201) at a concentration of $1 \times 10^{6}$ cells $/ \mathrm{mL}$. Cells were then incubated with $0.5 \mu \mathrm{g} / \mathrm{mL}$ Annexin V-FITC and $10^{-2} \mu \mathrm{g} / \mathrm{mL}$ PI during $15 \mathrm{~min}$. After incubation, $400 \mu \mathrm{L}$ of the Annexin V binding buffer was added to cell suspensions. 60,000 events per sample were recorded using the FC 500 Beckman Coulter (Brea, CA, USA). Data were analyzed by the Kaluza Analysis Software (version 1.5.20365.16139).

\section{Proliferation assays}

Cell cycle status was evaluated using Ki67-FITC and PI labeling and flow cytometry. $1 \times 10^{6}$ cells were harvested $48 \mathrm{~h}$ post-transfection and fixed in $3 \mathrm{~mL}$ cold ethanol (70\%) during $90 \mathrm{~min}$. Cells were resuspended in $1 \mathrm{~mL}$ of cell staining buffer (Biolegend, 420201). $100 \mu \mathrm{L}$ of cell suspensions were incubated with $0.06 \mu \mathrm{g} / 5 \mu \mathrm{L}$ Ki67-FITC during $30 \mathrm{~min}$. After incubation, cells were washed with cell staining buffer, resuspended in $500 \mu \mathrm{L}$ of cell staining buffer and incubated with $10^{-2} \mu \mathrm{g} / \mathrm{mL}$ PI. 60,000 events per sample were analyzed by flow cytometry using the FC 500 Beckman Coulter (Brea, CA, USA). The cell cycle status was determined as previously described ${ }^{34}$.

\section{Cell migration and invasion assays}

Transwell cell migration assays were performed using BD Falcon Cell Culture Inserts. MDA-MB-231 and BT549 cells expressing Src mutants were pre-incubated in serum-free medium (DMEM supplemented with 0.1\% FBS) overnight. 25,000 cells resuspended in $200 \mu \mathrm{L}$ of serum-free medium were placed in the insert and allowed to migrate for $24 \mathrm{~h}$. The outer chamber was filled with $600 \mu \mathrm{L}$ of medium containing $20 \%$ FBS or with $600 \mu \mathrm{L}$ of serum-free medium (as negative control). After $24 \mathrm{~h}$, non-migrating cells were removed with a cotton swab and migrating cells were fixed with methanol during $20 \mathrm{~min}$ and stained with crystal violet. For invasion 
assays, inserts were pre-coated with $100 \mu \mathrm{L}$ matrigel $(500 \mu \mathrm{g} / \mathrm{mL})$ diluted in cold coating buffer $(0.01 \mathrm{M}$ Tris, $0.7 \% \mathrm{NaCl}, \mathrm{pH} 8$ ) during 2 h. 25,000 cells were seeded in matrigel-coated inserts. Then, invasion was evaluated as described for migration assays. Five adjacent quadrants at the center of each membrane were imaged at $\times 40$ magnification using the EVOS FL Auto 2 imaging system. Cells were counted (cell counts ranged from $<10$ to 800 per quadrant) and the mean number of cells/quadrant/ membrane was determined.

\section{LC-MS/MS}

Lysates of MDA-MB-231 cells expressing pcDNA or MLS-Src-HA were submitted to trypsin digestion and phospho-peptides enrichment using titanium dioxide (Pierce). Peptide samples were injected and separated by online reversed-phase (RP) nanoscale capillary liquid chromatography (nanoLC) and analyzed by electrospray mass spectrometry (ESI MS/MS). The experiments were performed with a Dionex UltiMate 3000 nanoRSLC chromatography system (Thermo Fisher Scientific / Dionex Softron GmbH, Germering, Germany) connected to an Orbitrap Fusion mass spectrometer (Thermo Fisher Scientific, San Jose, CA, USA). Peptides were eluted with a linear gradient of 5-40\% B (A: 0.1\% formic acid, B: $80 \%$ acetonitrile, $0.1 \%$ formic acid) for $120 \mathrm{~min}$ on a $75 \mathrm{u} \mathrm{x} 50 \mathrm{~cm}$ Acclaim Pepmap (ThermoFisher) column at $300 \mathrm{nl} / \mathrm{min}$. Raw data were then analyzed by Mascot and Scaffold softwares to identify proteins and phospho-peptides using the database Uniprot Ref Homo sapiens (93675 entries). Quantitative analysis of phospho-peptide levels was performed using MaxQuant (version 1.6.0.16). Differences were considered significant between the two conditions when the $P$-value $<0.05$ and the $Z$-score $>1.96$ (i.e., outside the 95\% confidence interval). Phospho-peptide enrichment, digestion and mass spectrometry were performed by the Proteomics Platform of the CHU de Quebec research center, Quebec city, Quebec, Canada.

\section{Levels of mtDNA}

Total DNA was isolated from MDA-MB-231 cells using standard protocols. The relative amount of mtDNA was examined by real-time PCR as described ${ }^{35}$. Primers sequences for the mitochondrial gene MT-ND5 (326 bp) were: forward: 5'-AGGCGC-TATCACCACTCTGTTCG3', reverse: 5'-AACCTGTGAGGAAAGGTATTCCTG-3'. Primers for the nuclear gene CFTR (460 bp) were: forward: 5'-ACAGAAGCGTCATCAAAGCA-3', reverse: 5'-AGCT TACCCATAGAGGAAA-CATAA-3'. PCR was performed in $10 \mu \mathrm{l}$ reaction volume containing $2 \mathrm{mM} \mathrm{MgCl}_{2}$, $0,5 \mu \mathrm{M}$ each of the forward and reverse primers, $4 \mu \mathrm{l}$ of DNA (5 ng) and $1 \mu \mathrm{l}$ of master mixture (LightCycler-Fast Start DNA master SYBR Green I; Roche) containing
TaqDNA polymerase, deoxynucleotide triphosphates and SYBR Green I. The same DNA dilutions were used for both nuclear DNA and mtDNA calibration curves with a standard DNA. The reaction was conducted as follows: an initial denaturing step at $95{ }^{\circ} \mathrm{C}$ for $3 \mathrm{~min}$, followed by 50 cycles at $95^{\circ} \mathrm{C}$ for $10 \mathrm{~s}, 60^{\circ} \mathrm{C}$ for $30 \mathrm{~s}$, with acquisition mode at segment 2 . Samples were analyzed in triplicate and the number of copies of mtDNA was calculated as $2 \times 2^{\Delta \mathrm{Ct}}$, where $\Delta \mathrm{Ct}=\mathrm{Ct}_{\mathrm{CFTR}}-\mathrm{Ct}_{\mathrm{ND} 5}$, as described ${ }^{36}$.

\section{Statistical analyses}

Statistical analyses were performed using GraphPad software (version 7.02). Quantitative analysis of phosphopeptide levels was performed using MaxQuant (version 1.6.0.16). Results are expressed as mean of independent data points \pm s.e.m. Data were analyzed using Student $T$ test, one-way (followed by Tukey's post hoc test) or twoway ANOVA (followed by Dunnett's post hoc test), as appropriate. Significance was assessed at $p \leq 0.05$.

\section{Results \\ Activity of $\mathrm{mtSrc}$ is higher in TNBC cells}

We first characterized the levels and activity of total Src and $\mathrm{mtSrc}$ in different subcellular fractions obtained from control breast epithelial cells, triple negative cells, HER2positive cells and ER-PR-positive cells. Immunoblotting of the cytosolic marker tubulin and of the mitochondrial marker succinate dehydrogenase subunit a reveal the purity of the cytosolic and mitochondria-enriched fractions obtained by differential centrifugation (Fig. 1a). These immunodetection assays also revealed that Src is present both in cytosolic- and mitochondrial-enriched fractions in all of the cell lines tested (Fig. 1a). Only the HER2+ MDA-MB-453 cell line has low (if any) levels of Src (Fig. 1a, b), in accordance with previous works ${ }^{37,38}$. Direct comparison of total cell lysates by immunoblotting revealed no clear difference in total Src levels or activity specific to BC subtypes (Fig. 1b and Supplementary Fig. 1a, b). However, when Src levels and activity were compared among mitochondrial fractions, the activity of $\mathrm{mtSrc}$ appeared significantly higher in triple negative MDA-MB-231, MDA-MB-468 and BT549 cells than in other cell lines (Fig. 1c and Supplementary Fig. 1c, d). These results suggest that $\mathrm{mtSrc}$ signaling is involved in the specific phenotype of TNBC.

\section{MtSrc alters mitochondrial metabolism}

To examine the specific role of $\mathrm{mtSrc}$ in TNBC cells, we generated a mutant of Src specifically targeted to mitochondria by fusing the mitochondrial leading sequence (MLS) of cytochrome c oxidase subunit VIII (amino acids 1-31) to the N-terminus of mouse Src (Fig. 2a). To discriminate between endogenous and ectopic Src, the tag hemagglutinin (HA) was added to the C-terminus of Src 


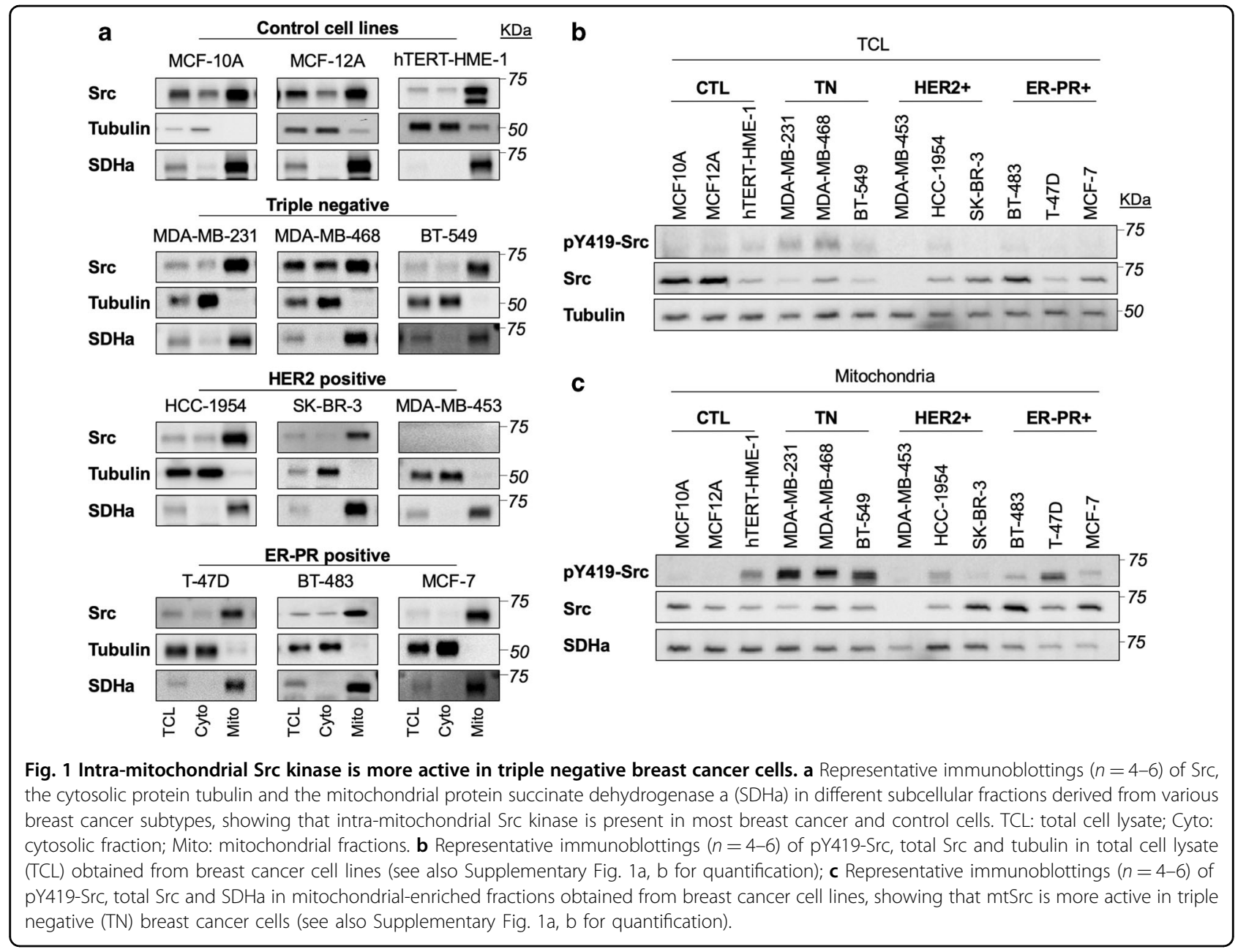

(Fig. 2a). Immunodetection of $\mathrm{HA}$ and mitochondrial protein TOM20 in MDA-MB-231 expressing control pcDNA vector, Src-HA or MLS-Src-HA by confocal microscopy revealed that Src-HA spreads throughout the cell, whereas MLS-Src-HA is specifically addressed to mitochondria (Fig. 2b). Immunoblottings confirmed that both constructs generate higher levels and higher activity of $\mathrm{Src}$ in specific subcellular compartments (Fig. 2c). These results indicate that Src-HA and MLS-Src-HA represent suitable tools to discriminate between extraand intra-mitochondrial Src.

The functional impact of both Src mutants was then examined in TNBC cells. We first evaluated different respiratory states of intact MDA-MB-231, MDA-MB-468 and BT-549 cells. Overexpression of Src-HA significantly decreased most respiration states in TNBC cells (Fig. 2d). Overexpression of Src only in mitochondria was sufficient to inhibit cellular respiration (Fig. 2d). Similarly, mitochondrial membrane potential, an important parameter of OXPHOS, decreased upon expression of mtSrc, as indicated by lower TMRM fluorescence in MDA-MB-
231 cells expressing MLS-Src-HA (Fig. 2e and Supplementary Fig. 2a). Alterations of OXPHOS induced by expression of MLS-Src-HA did not induced variation in superoxide production, as indicated by labeling of MitoSox $^{\mathrm{TM}}$ in MDA-MB-231 expressing Src mutants (Fig. 2f and Supplementary Fig. 2b). Src mutants could decrease cellular respiration via reduction of global mitochondrial mass. We then examined whether Src mutants decrease cellular respiration via reduction of global mitochondrial mass using two approaches. MDAMB-231 cells expressing Src mutants were labeled with MitoTracker Green ${ }^{\mathrm{TM}}$ which labels mitochondria independently of the mitochondrial membrane potential. Results obtained indicate that both Src mutants does not affect OXPHOS via reduction of mitochondrial mass (Fig. $2 \mathrm{~g}$ and Supplementary Fig. 2c). Immunoblotting of a panel of mitochondrial proteins confirmed that mtSrc does not reduce levels of mitochondrial proteins (Supplementary Fig. 2d). Altogether, these results suggest that $\mathrm{mtSrc}$ induces OXPHOS defects via post-translational modification of mitochondrial protein(s). 


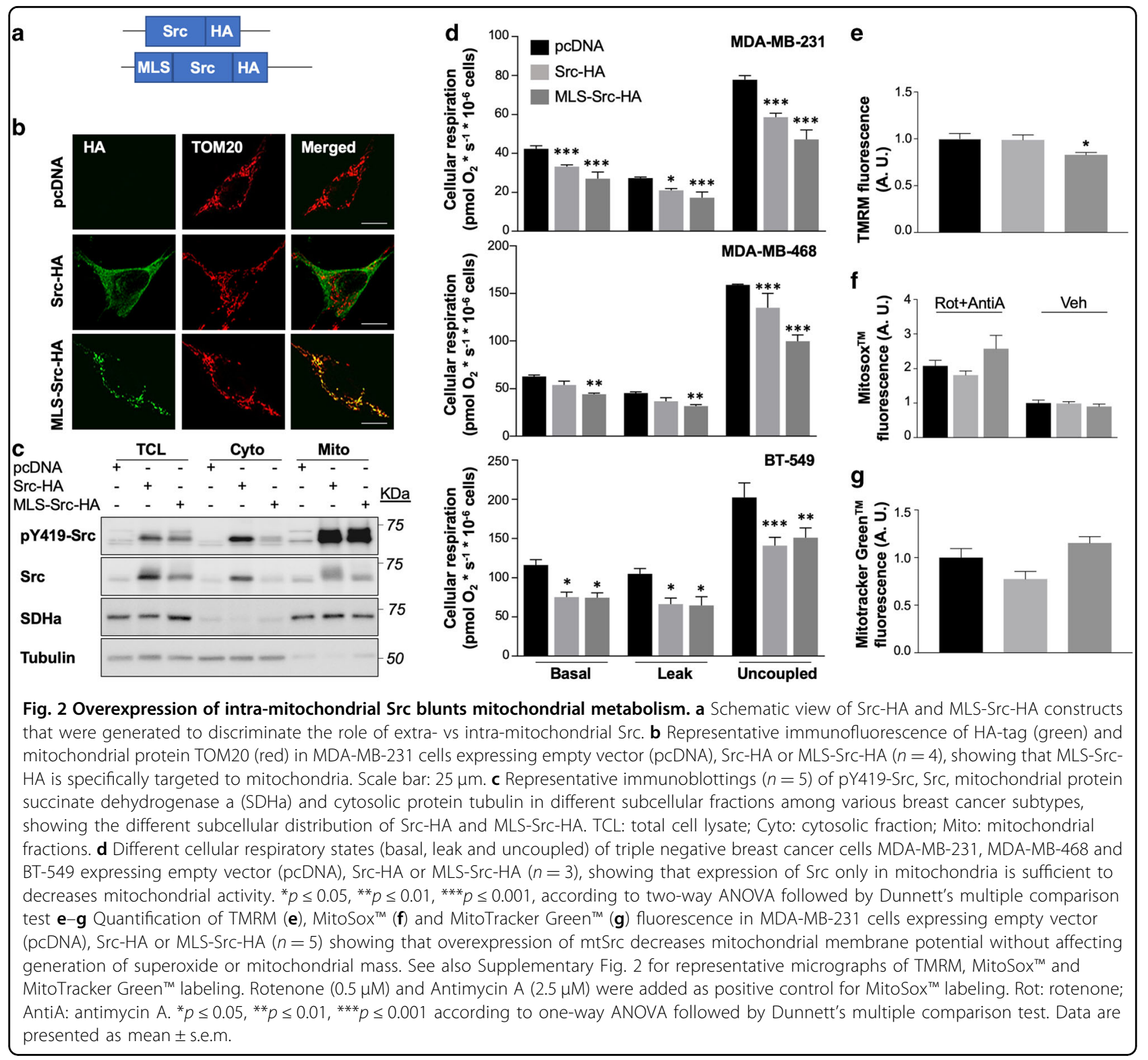

Cells grown in high-glucose media are usually highly glycolytic, as previously reported ${ }^{26,39,40}$. Indeed, ATP levels derived from mitochondrial metabolism are low compared to ATP generated from glycolysis in MDA-MB-231 cells grown in high-glucose DMEM (Fig. 3a). OXPHOSdependent ATP levels can be increased when cells are grown in DMEM where glucose was replaced by galactose (Fig. 3a), as previously observed ${ }^{26,41}$ We thus examined the impact of mtSrc in DMEM containing galactose to determine whether $\mathrm{mtSrc}$-dependent alterations of mitochondrial activity is restricted to highly glycolytic conditions. Overexpression of $\mathrm{mtSrc}$ had similar impact on cellular respiration, mitochondrial membrane potential, superoxide levels and mitochondrial mass in MDA-MB-231 cells grown in DMEM containing galactose (Fig. $3 \mathrm{~b}-\mathrm{e}$ and
Supplementary Fig. 3) as compared to cells maintained in DMEM containing glucose (Fig. $2 \mathrm{c}-\mathrm{f}$ and Supplementary Fig. $2 \mathrm{a}-\mathrm{c}$ ). Our findings suggest that the $\mathrm{mtSrc}$-dependent modulation of mitochondrial metabolism is not specific to TNBC glycolytic phenotype. Expression of Src mutants in MDA-MB-453 cells (Fig. 3f), which have low levels of endogenous Src (Fig. 1 and Supplementary 1) also inhibited cellular respiration (Fig. 3g). These findings indicate that $\mathrm{mtSrc}$-dependent regulation of cellular respiration is not restricted to TNBC cells and/or cells with high endogenous levels of (mt)Src.

\section{MtSrc modulates cellular viability and proliferation}

Mitochondrial functions are involved in the neoplasic phenotype of cancer cells ${ }^{5}$. We thus hypothesized that 

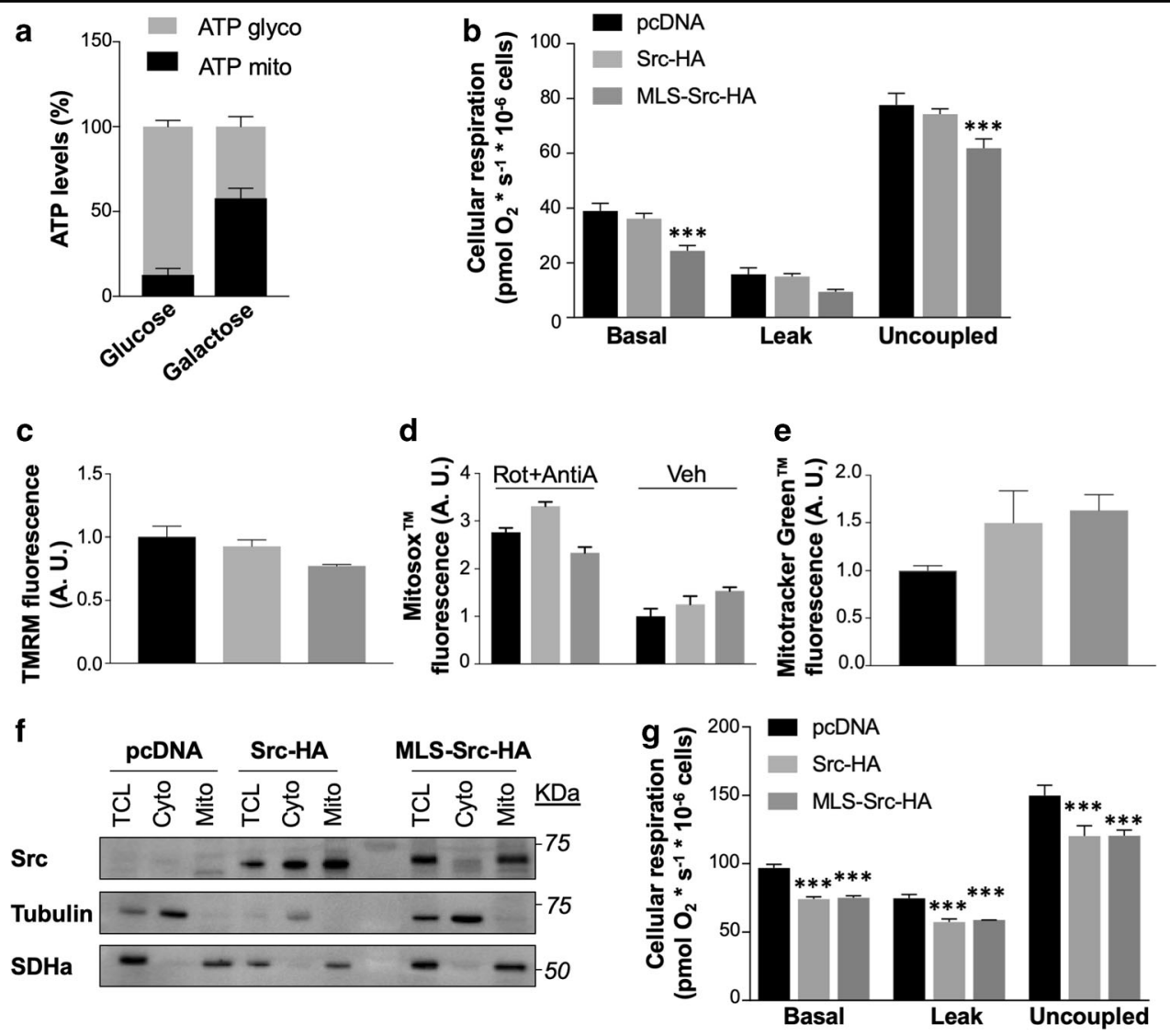

Fig. 3 Mitochondrial alterations induced by intra-mitochondrial Src are not restricted to highly glycolytic triple negative cells. a ATP levels derived from glycolysis (ATP glyco) and mitochondrial metabolism (ATP mito) in MDA-MB-231 cells maintained in DMEM containing glucose or galactose $(n=5)$, showing that high glycolytic phenotype of cells cultured in DMEM with glucose can be modified to a more oxidative phenotype when glucose is replaced by galactose. $\mathbf{b}$ Different cellular respiratory states (basal, leak and uncoupled) of MDA-MB-231 cells expressing empty vector (pcDNA), Src-HA or MLS-Src-HA and maintained in DMEM containing galactose $(n=5)$, showing that mtSrc-dependent mitochondrial dysfunction decreases mitochondrial activity in pro-oxidative metabolism conditions. *** $p \leq 0.001$, according to two-way ANOVA followed by Dunnett's multiple comparison test. c-e Quantification of TMRM (c), MitoSox ${ }^{\mathrm{TM}}(\mathbf{d})$, and MitoTracker Green ${ }^{\mathrm{TM}}$ (e) fluorescence in MDA-MB-231 cells expressing empty vector (pcDNA), Src-HA or MLS-Src-HA and cultured in DMEM containing galactose $(n=3)$. See also Supplementary Fig. 3 for representative micrographs of TMRM, MitoSox ${ }^{\mathrm{TM}}$ and MitoTracker Green ${ }^{\mathrm{TM}}$ labeling. Rotenone $(0.5 \mu \mathrm{M})$ and Antimycin A $(2.5 \mu \mathrm{M})$ were added as positive control for MitoSox ${ }^{\mathrm{TM}}$ labeling. Rot: rotenone; AntiA: antimycin A. f Representative immunoblottings $(n=3)$ of $\operatorname{Src}$, mitochondrial protein succinate dehydrogenase a (SDHa) and cytosolic protein tubulin in different subcellular fractions derived from HER2-positive MDA-MB-453 cells expressing empty vector (pcDNA), Src-HA or MLS-Src-HA. TCL: total cell lysate; Cyto: cytosolic fraction; Mito: mitochondrial fractions. $\mathbf{g}$ Different cellular respiratory states (basal, leak and uncoupled) of MDA-MB-453 cells expressing empty vector (pcDNA), Src-HA or MLS-Src-HA ( $n=3$ ), showing that $\mathrm{mtSrc}$-dependent mitochondrial dysfunction is not restricted to triple negative breast cancer cells. Data are presented as mean $\pm s . e . m$. ${ }^{* * *} p \leq$ 0.001, according to two-way ANOVA followed by Dunnett's multiple comparison test.

mtSrc-dependent alterations of mitochondrial metabolism could affect the phenotype of TNBC cells. To address this, we examined how mtSrc impacts on apoptotic, proliferative, invasion and migration capacities of MDAMB-231 cells. MDA-MB-231 cells expressing control vector, Src-HA or MLS-Src-HA grown in high-glucose or galactose media were labeled with Annexin V-FITC and PI to characterize the impact of $\mathrm{mtSrc}$ on cellular viability. Expression of Src-HA had no effect on cell death whereas expression of MLS-Src-HA resulted in significant reduction of viable cells and increase in necrotic cells grown in high-glucose (Fig. 4a). When glucose was replaced by galactose in culture media, overexpression of $\mathrm{mtSrc}$ decreased the number of viable cells but increased late apoptotic cells (Supplementary Fig. 4a). MDA-MB-231 cells were then treated with the apoptotic inducer actinomycin $\mathrm{D}$ (Act. D) to evaluate the role of $\mathrm{mtSrc}$ during pro-apoptotic conditions. Expression of Src-HA had no impact on viability of Act. D-treated cells compared to cells expressing control vectors (Fig. 4a and Supplementary Fig. 4a). However, expression of MLS-Src-HA significantly reduced early apoptosis and increased necrosis in cells treated with Act. D, independently of their metabolic phenotype (Fig. 4a and Supplementary Fig. 4a). 


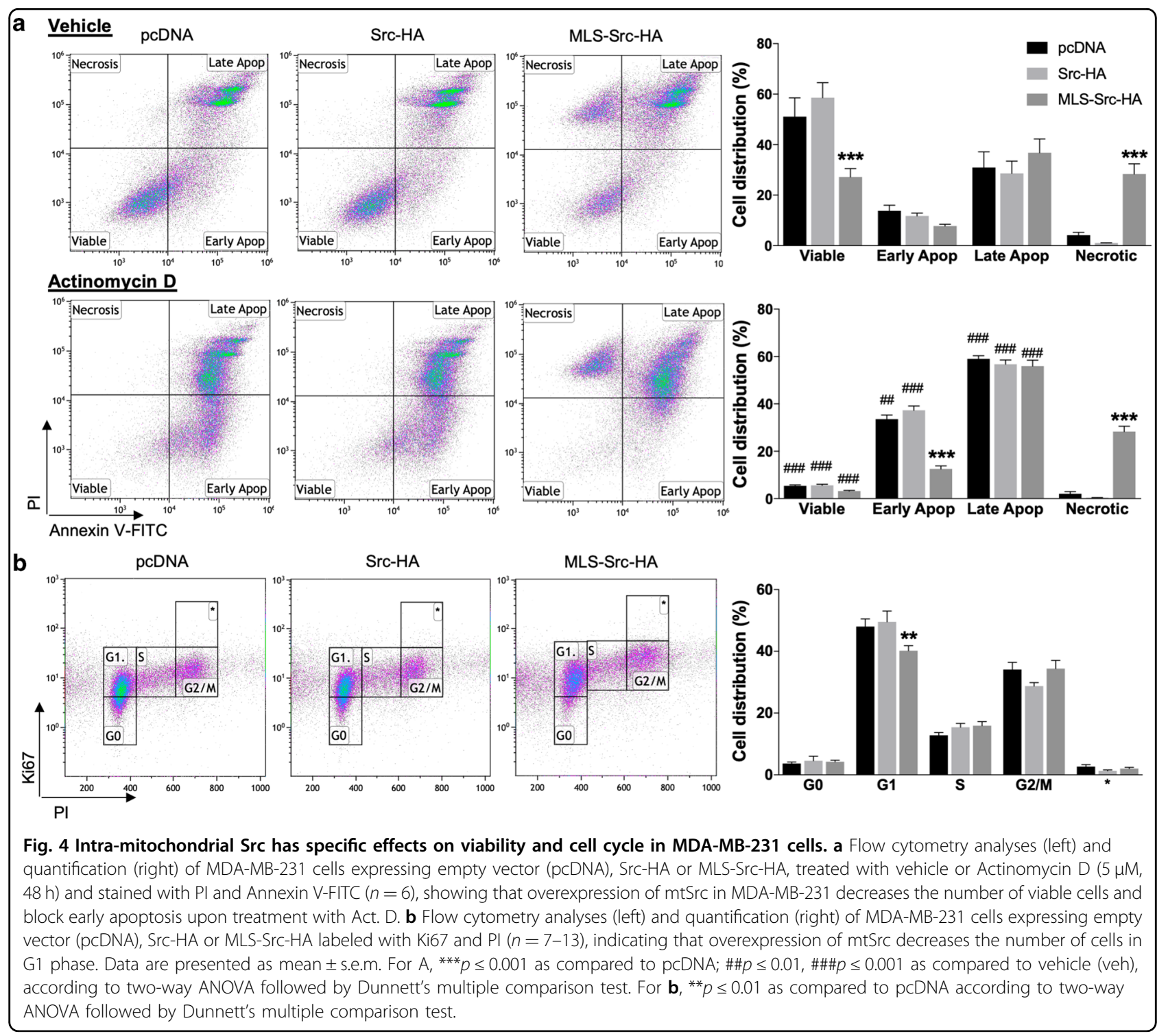

Expression of MLS-Src-HA also blocked the increase of early apoptotic cells induced by Act. D (Fig. 4a and Supplementary Fig. 4a). Overall, these findings indicate that $\mathrm{mtSrc}$ activity modulates cellular viability and apoptosis per se and partly blocks the sensitivity of MDA-MB231 cells to the apoptotic inducer Act. D.

Cells expressing Src mutants were labeled with PI and the proliferation marker Ki67 to examine the impact of mtSrc on cell cycle and cellular proliferation, as described ${ }^{34}$. In both metabolic conditions (high-glucose vs galactose DMEM), expression of Src-HA had no effect on cell cycle status. In high-glucose DMEM, expression of $\mathrm{mtSrc}$ significantly decreased numbers of cells in G1 phase (Fig. 4b). When cells were maintained in galactose DMEM, the number of cells in G1 phase was significantly lower whereas number of cells in G2/M was increased (Supplementary Fig. $4 \mathrm{~b})$, indicating that $\mathrm{mtSrc}$ shortens the cell cycle and accelerates proliferation. We then examined the impact of Src overexpression in migration and invasion capacities of TNBC cells. The findings obtained suggest that (mt)Src has no impact on migration in MDA-MB-231 and BT549 cells (Fig. 5a, c and Supplementary Fig. 5a, c). However, invasiveness of MDA-MB-231 and BT549 cells expressing either Src-HA and MLS-Src-HA was increased when cells were maintained in galactose media (Fig. 5b, d and Supplementary Fig. 5b, d), indicating that $\mathrm{mtSrc}$ increases invasion capacities in pro-OXPHOS conditions. Overall, our findings indicate that the $\mathrm{mtSrc}$-dependent remodeling of metabolism is crucial in the development of malignancy of TNBC.

\section{MtSrc does not impact on mitochondria via COXII and EGF signaling}

Src targets several mitochondrial proteins ${ }^{30}$. Conversely, expression of MLS-Src-HA in MDA-MB-231 cells increased 
a
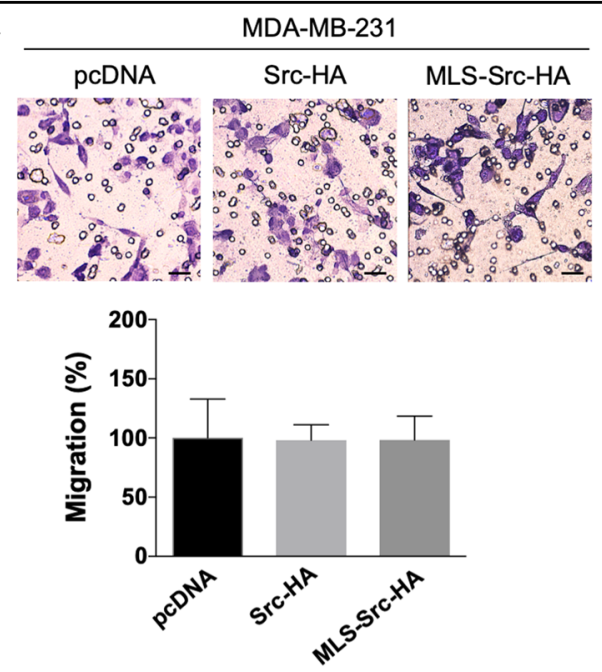

b
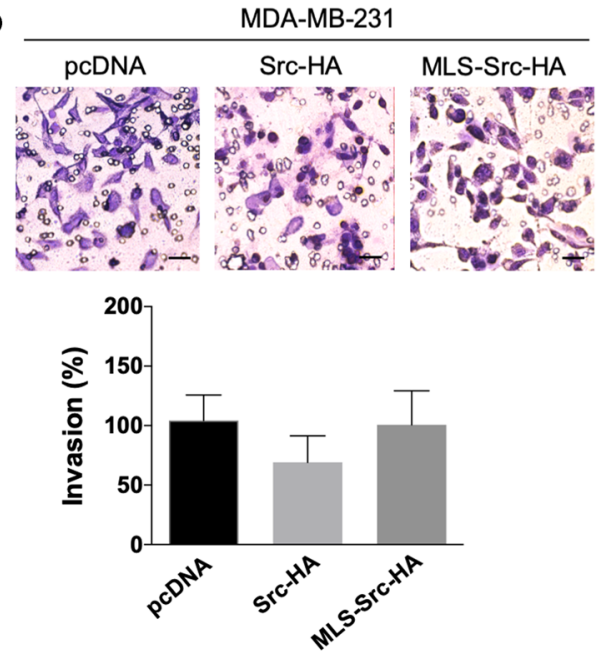

c
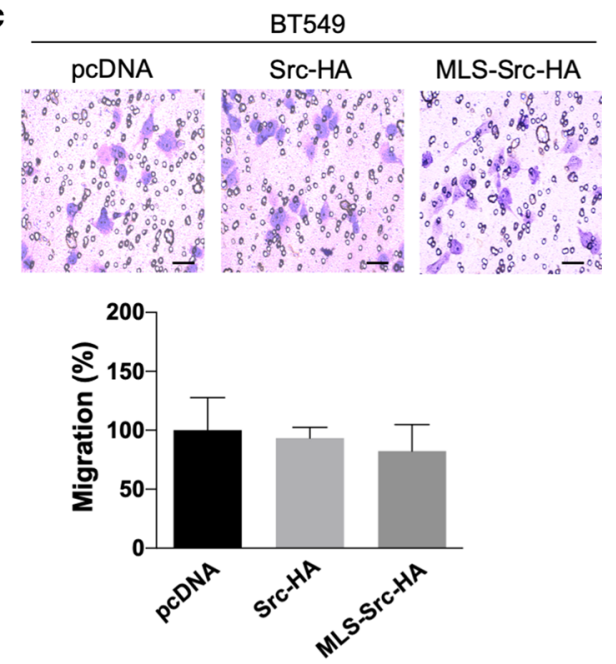

d
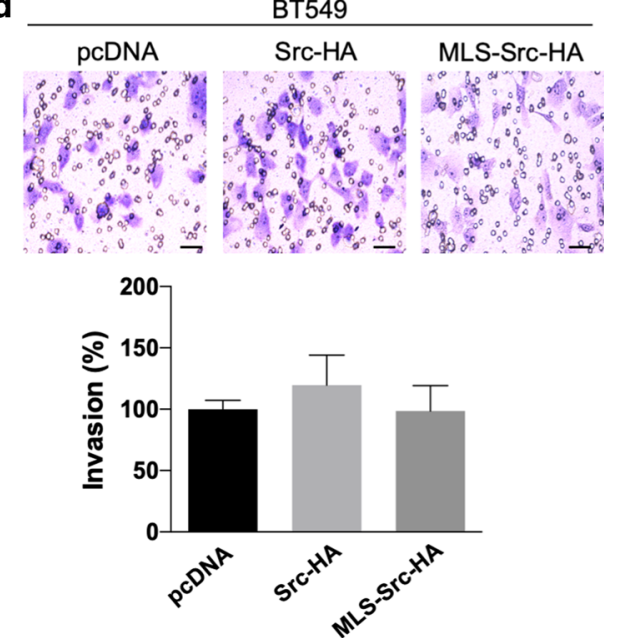

Fig. 5 Migration and invasion capacities upon expression of $(\mathbf{m t})$ Src in MDA-MB-231 and BT549 cells. a Representative micrographs and quantification of transwell assays without matrigel to evaluate migration of MDA-MB-231 cells expressing empty vector (pcDNA), Src-HA or MLS-SrcHA $(n=5)$. b Representative micrographs and quantification of transwell assays with matrigel to evaluate invasion capacities of MDA-MB-231 cells expressing empty vector (pcDNA), Src-HA or MLS-Src-HA $(n=5)$. c Representative micrographs and quantification of transwell assays without matrigel to evaluate migration of BT549 cells expressing pcDNA, Src-HA or MLS-Src-HA $(n=5)$. d Representative micrographs and quantification of transwell assays with matrigel to evaluate invasion capacities of BT549 cells expressing empty vector pcDNA, Src-HA or MLS-Src-HA $(n=5)$. Scale bar: $50 \mu \mathrm{m}$. Data are presented as mean \pm s.e.m. Data were analyzed by one-way ANOVA.

tyrosine-phosphorylation of several mitochondrial proteins (Fig. 6a). The subunit II of cytochrome $c$ oxidase (COXII) was the first protein identified as a target of $\mathrm{mtSrc}^{25}$. Later, it was shown that COXII can be phosphorylated by mtSrc upon treatment with epidermal growth factor (EGF) ${ }^{27}$. Considering these findings, we examined whether the $\mathrm{mtSrc}$-dependent regulation of mitochondrial metabolism observed here is linked to EGF- and Src-dependent phosphorylation of COXII. Immunoprecipitation of COXII revealed that overexpression of $\mathrm{mtSrc}$ does not increase tyrosine-phosphorylation of COXII in MDA-MB-231 cells (Supplementary Fig. 6a). Also, no variation in tyrosine- phosphorylation of COXII after treatment with EGF was observed (Supplementary Fig. 6a). Activation and translocation of Src into mitochondria were previously shown to be increased upon EGF treatment ${ }^{27}$. No variation in $\mathrm{mtSrc}$ activity and translocation of Src into mitochondria upon treatment with EGF was however observed (Supplementary Fig. 6b, c). EGF-dependent phosphorylation of COXII was shown to lower ATP levels in MDA-MB-231 cells ${ }^{27}$. EGF had however no impact on cellular respiration of MDA-MB231 cells (Supplementary Fig. 6d). Overall, these results suggest that $\mathrm{mtSrc}$ and EGF signaling are independent in MDA-MB-231. 


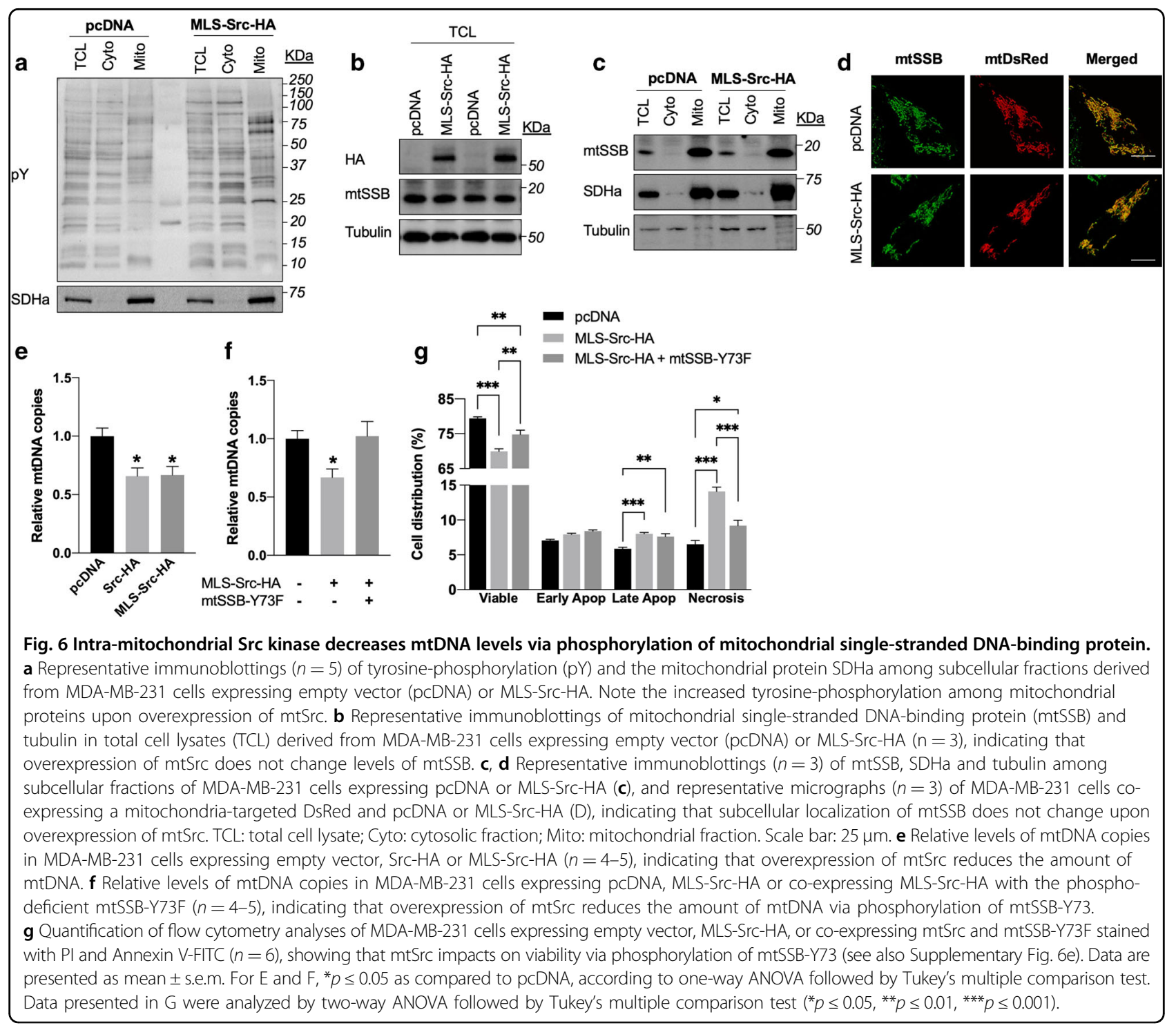

\section{MtSrc increases phosphorylation of $\mathrm{mtSSB}$ and reduces mtDNA levels}

To identify the target(s) of mtSrc, we quantitatively analyzed phospho-proteins in MDA-MB-231 cells expressing either empty vector or MLS-Src-HA by LCMS/MS. As shown in Table 1, 18 phospho-peptides were significantly more abundant upon overexpression of mtSrc. Gene ontology enrichment analyses (performed using Gene Ontology Unifying Biology online tool, http:// geneontology.org/) revealed an over-representation of genes involved in cadherin binding (five genes out of 18 [TBC1D2, MICALL1, SCRIB, PLEC, DLC1], representing a 17,5 -fold enrichment as compared to the total human genome, $p<0,001)$. Among the 18 proteins identified, only the mitochondrial single-stranded DNA-binding protein $(\mathrm{mtSSB})$ is located inside the organelle and thus proximal to $\mathrm{mtSrc}$, suggesting it is directly phosphorylated by $\mathrm{mtSrc}$.
Phosphorylated mtSSB was 34-fold more abundant following expression of MLS-Src-HA (Table 1). Moreover, mtSSB was the only phospho-peptide for which a tyrosine residue was identified as the putative phosphorylation site (i.e., Y73, see Supplementary Table 1). We therefore examined levels, subcellular localization and activity of $\mathrm{mtSSB}$ upon overexpression of $\mathrm{mtSrc}$ in MDA-MB-231. We first observed that expression of MLS-Src-HA does not change the total levels of mtSSB (Fig. 6b), indicating that the higher level of phosphorylation of $\mathrm{mtSSB}$ upon overexpression of $\mathrm{mtSrc}$ is not due to higher levels of mtSSB per se. Immunofluorescence and immunoblotting of mtSSB in subcellular compartments revealed that overexpression of $\mathrm{mtSrc}$ and phosphorylation of mtSSB does not change the intra-mitochondrial localization of the protein (Fig. 6c, d). Since mtSSB is required for the maintenance 
Table 1 Phospho-proteins identified by LC-MS/MS upon expression of $\mathrm{mtSrc}$.

\begin{tabular}{|c|c|c|c|c|}
\hline Protein name & Gene name & Ratio & $P$ value & GO molecular function \\
\hline Single-stranded DNA-binding protein, mitochondrial & SSBP1 & 34.40 & $p<0.05$ & DNA and RNA binding \\
\hline Probable ATP-dependent RNA helicase DDX47 & DDX47 & 17.57 & $p<0.01$ & ATP and RNA binding \\
\hline Serine/arginine-rich splicing factor 1 & SRSF1 & 13.54 & $p<0.05$ & RNA binding \\
\hline Pumilio homolog 2 & PUM2 & 11.62 & $p<0.05$ & mRNA binding \\
\hline TBC1 domain family member $2 \mathrm{~A}$ & TBC1D2 & 9.90 & $p<0.05$ & Cadherin binding \\
\hline Caskin-2 & CASKIN2 & 8.92 & $p<0.001$ & No biological data available \\
\hline Probable ATP-dependent RNA helicase DDX20 & DDX20 & 8.91 & $p<0.01$ & ATP and DNA binding \\
\hline MICAL-like protein 1 & MICALLI & 8.51 & $p<0.05$ & Cadherin binding \\
\hline Protein TANC2 & TANC2 & 7.79 & $p<0.01$ & No biological data available \\
\hline TMEM63B & TMEM63B & 7.06 & $p<0.05$ & Calcium channel activity \\
\hline Protein scribble homolog & $S C R I B$ & 6.51 & $p<0.05$ & Cadherin binding \\
\hline Cytochrome b reductase 1 & CYBRD1 & 6.17 & $p<0.05$ & Oxidoreductase activity \\
\hline Ankyrin repeat and IBR domain-containing protein 1 & ANKIB1 & 5.89 & $p<0.05$ & Ubiquitin-ligase activity \\
\hline Plectin & PLEC & 5.55 & $p<0.05$ & Cadherin binding \\
\hline Rho guanine nucleotide exchange factor 2 & ARHGEF2 & 5.35 & $p<0.01$ & Rho-GTPase activity \\
\hline Eukaryotic translation initiation factor 4 gamma 2 & EIF4G2 & 5.25 & $p<0.01$ & mRNA binding \\
\hline Insulin receptor substrate 2 & IRS2 & 4.97 & $p<0.05$ & Insulin receptor binding \\
\hline Rho GTPase-activating protein 7 & $D L C 1$ & 4.92 & $p<0.05$ & Rho-GTPase activity \\
\hline
\end{tabular}

Phospho-peptides were characterized from lysates derived from MDA-MB-231 cells expressing empty vector (pcDNA) or MLS-Src-HA. Ratio represents the number of phospho-peptides observed in cells expressing MLS-Src-HA to cells expressing pcDNA. Note that only phospho-peptides significantly more abundant in cells expressing MLS-Src-HA are shown. Go molecular functions were obtained from Uniprot (https://www.uniprot.org/). See Supplementary Table 1 for the complete dataset.

Supplemental Table 1. Complete dataset for LC-MS/MS analyses of phospho-peptides in MDA-MB-231 cells expressing pcDNA and MLS-Src-HA

of $\mathrm{mtDNA}^{42,43}$, we measured levels of $\mathrm{mtDNA}$ as an index of mtSSB activity. Strikingly, we observed that overexpression of (mt)Src results in lower mtDNA levels (Fig. 6e), suggesting that $\mathrm{mtSrc}$-dependent phosphorylation of mtSSB reduces its replication activity. To address this, we generated a phospho-deficient mutant of mtSSB-Y73 (i.e., mtSSB-Y73F). Then, mtDNA levels were compared among MDA-MB-231 cells expressing control vector, MLS-Src-HA and MLS-Src-HA with $\mathrm{mtSSB}-Y 73 F$. Strikingly, co-expression of $\mathrm{mtSSB}$ phospho-deficient and MLS-Src-HA completely prevented the reduction of mtDNA levels induced by $\mathrm{mtSrc}$ expression (Fig. 6f). Similarly, co-expression of the same constructs prevented the changes in number of viable cells and necrotic cells induced by over-expression of $\mathrm{mtSrc}$ (Fig. $6 \mathrm{~g}$ and Supplementary Fig. 6e), indicating that $\mathrm{mtSrc}$ impacts on TNBC cells via phosphorylation of mtSSB-Y73.

Overall, our results demonstrate that higher activation of $\mathrm{mtSrc}$ increases phosphorylation of $\mathrm{mtSSB}$ to reduce mtDNA levels, inducing OXPHOS deficits, lower viability, shorter cell cycle and increased invasiveness in TNBC cells.

\section{Discussion}

Alterations in mitochondrial functions and Src kinase activity are involved in the physiopathology of cancer. The role of intra-mitochondrial Src in this context remains however scantly studied. The aim of this work was to characterize the role of $\mathrm{mtSrc}$ in the metabolic and neoplasic phenotype of $\mathrm{BC}$ cells. Our findings indicate that $\mathrm{mtSrc}$ is more active in TNBC and that overexpression of $\mathrm{mtSrc}$ alters the metabolic and neoplasic behavior of TNBC cells via phosphorylation of mtSSB. This work therefore illustrates that $\mathrm{mtSrc}$ links alterations in mitochondrial metabolism to the aggressive phenotype of TNBC cells.

The present work identified a new target for mtSrc since its overexpression increases phosphorylation of $\mathrm{mtSSB}-\mathrm{Y73}$. Phosphorylation of mtSSB-Y73 has been observed in various type of cancer, including $\mathrm{BC}^{44-50}$. This protein is a key component of the mitochondrial replisome and is required for the mtDNA maintenance and replication. MtSSB binds and organizes template DNA, leading to stimulation of the mtDNA helicase Twinkle and the polymerase $\gamma^{42,43}$. Reduction in mtDNA copy number and the maintenance of mtDNA levels by 
mtSSB has been associated with metabolic reprogramming and aggressive features such as increased metastatic potential and chemoresistance in various types of cancer $^{51,52}$. Knock-down of mtSSB decreases mtDNA copy number and proliferation in different types of cancer cells, including Hela and $143 \mathrm{~B}^{53,54}$. Silencing of mtSSB in human lung cancer cell line $\mathrm{H} 1299$ results in mitochondrial dysfunction and sensitization to ionizing radiation $^{55}$. Interestingly, analysis of the Cancer Genome Atlas breast cancer dataset revealed that TN tumors have decreased mtDNA copy numbers ${ }^{56}$, whereas low mtSSB expression correlates with poor clinical outcomes $^{57}$. In $\mathrm{BC}$, silencing mtSSB decreases mtDNA levels and mitochondrial membrane potential, which trigger mitochondrial retrograde signaling mediated by calcineurin A resulting in increased epithelial-tomesenchymal transition and metastatic potential in TNBC MDA-MB-231 and MDA-MB-468 cells ${ }^{57}$. Here, we observed that $\mathrm{mtSrc}$ increases tyrosinephosphorylation of mtSSB-Y73F and reduces mtDNA levels. We therefore propose that $\mathrm{mtSrc}$ modulates metabolic and neoplasic phenotype of TNBC cells (at least partly) via phosphorylation of mtSSB. Our findings also demonstrate that extra- and intra-mitochondrial Src have different functional impacts on TNBC cells. Indeed, only MLS-Src-HA altered viability and cell cycle status although expression of Src-HA and MLS-Src-HA generated similar levels of ectopic mtSrc. It is thus possible that targets of extra-mitochondrial Src counteract some of the functionnal impact of $\mathrm{mtSrc}$-mediated phosphorylation of $\mathrm{mtSSB}$.

The present study suggests that $\mathrm{mtSrc}$ is central in the specific metabolic phenotype of TNBC cells. These cells exhibit higher glucose uptake and lactate production as well as lower mitochondrial metabolism than other BC subtypes $^{7,56}$. Increased capacities of TNBC cells for metastasis is also linked to defects in mitochondrial dynamics ${ }^{10}$. Lower levels of mitophagy-related BNip3 is commonly found in TBNC, leading to defective mitochondria and higher metastatic potential ${ }^{58}$. Mitochondrial dysfunctions induced by lower mtDNA levels and/ or altered OXPHOS can lead to $\mathrm{Ca}^{2+}$-dependent mitochondrial retrograde signaling, and activation of different pathways, such as nuclear translocation of NF-kB, important for metabolic reprogramming, induction of epithelial-to-mesenchymal transition, increased metastasis, and apoptosis resistance ${ }^{59}$. Rescuing mitochondrial activity could therefore represent a potent therapeutic strategy for TNBC. Increased complex I activity inhibits tumor growth and metastasis in TNBC ${ }^{60}$. Reactivation of mitochondrial metabolism by expression of mitochondrial pyruvate carrier also impairs the ability of different cancer cells to grow ${ }^{61-63}$. Strikingly, Src induces phosphorylation and inhibition of pyruvate dehydrogenase ${ }^{64}$, the enzyme responsible for the conversion of pyruvate into acetyl-CoA. Our results suggest that $\mathrm{mtSrc}$-dependent reduction of mtDNA levels lead to OXPHOS deficiency and a more aggressive phenotype. Inhibitors specific for $\mathrm{mtSrc}$ could therefore restore mitochondrial activity in TNBC cells, and ultimately stop malignancy. It will be important to characterize the ability of known inhibitors and/or activators of Src to target $\mathrm{mtSrc}$, and examine their potency towards mitochondrial functions and tumorigenesis. The overall metabolic phenotype of TNBC cells also appears important to predict the effects of $(\mathrm{mt}) \mathrm{Src}$ activation. The present study shows that overexpression of $\mathrm{mtSrc}$ is able to increase invasion of MDA-MB-231 cells when they are maintained in a culture media that favors OXPHOS metabolism. Therefore, inhibition of Src could be even more beneficial in tumors using oxidative metabolism as compared to glycolytic tumors.

LC-MS/MS analyses showed that several proteins involved in cell-cell adhesion and invasion are also more phosphorylated upon overexpression of $\mathrm{mtSrc}$. Although the role of these phosphorylation events was not characterized, they are indicative of global changes leading to a more invasive and aggressive phenotype. The protein scribble localizes to cell-cell junctions and regulates several signaling pathways involved in cell migration, whereas mislocalization of scribble promotes cell transformation and neoplasic growth in breast cancer ${ }^{65,66}$. TBC1 domain family member $2 \mathrm{~A}$, also known as Armus, is involved in E-cadherin degradation during cell dispersion ${ }^{67}$. MICALlike protein 1 modulates invasion capacities via oxidative stress in breast cancer cells ${ }^{68}$. Plectin is a large intracellular protein which links cell-cell junctions, such as hemidesmosomes, to the cytoskeleton. Expression of plectin appears higher in cancer tissue and plectin-deficiency can result in higher migration ${ }^{69,70}$. The Rho guanine nucleotide exchange factor 2 (ARHGEF2, also known as GEF$\mathrm{H} 1$ ) is an oncoprotein that activates RhoA and is involved in cytoskeleton organization, cellular motility, invasion and proliferation ${ }^{71}$. Interestingly, expression of ARHGEF2 accelerates breast cancer invasion and metastasis ${ }^{72}$. Similarly, active Rho GTPase activating protein 7 induces cell detachment through cytoskeletal reorganization and increases cell migration ${ }^{73}$. Altogether, our findings suggest that $\mathrm{mtSrc}$ links alterations of mitochondrial physiology and invasiveness in TNBC cells.

In conclusion, the present work demonstrates that Src localized inside mitochondria has specific functional consequences in $\mathrm{BC}$. We observed that $\mathrm{mtSrc}$ makes TNBC more aggressive with alterations in mitochondrial metabolism and higher invasion. This work also identified a new target for $\mathrm{mtSrc}$, i.e., $\mathrm{mtSSB}$, which was already shown as a reliable prognostic marker in TNBC. Therefore, we propose that targeting $\mathrm{mtSrc}$ or its interactors 
should be considered in the generation of better therapeutic strategies for $\mathrm{BC}$.

\section{Acknowledgements}

We thank Yoav Henis (Tel Aviv University, Israel) who kindly provided the SrcGFP mutant. MDA-MB-231, MCF-7, T-47D, MCF-10A and MCF-12A cell lines were generously provided by the Atlantic Cancer Research Institute (Moncton, NB, Canada). We are also grateful to Sandra Turcotte and the Atlantic Canada Research Institute for access to confocal microscope. LC-MS/MS was performed by the Proteomics Platform of the CHU de Quebec research center, Quebec city, Quebec, Canada. This work was funded by the Canadian Cancer Society (2015-317342), Natural Sciences and Engineering Research Council of Canada (NSERC, RGPIN-2015-05880), Canadian Health Research Institute (CIHR, 388808), Canada Research Chair program, New Brunswick Health Research Foundation (NBHRF), New Brunswick Innovation Foundation and Université de Moncton. G. H-C. is supported by a NBHRF post-doctoral fellowship.

\section{Author details}

${ }^{1}$ Canada Research Chair in Mitochondrial Signaling and Physiopathology, Moncton, NB, Canada. ${ }^{2}$ Department of Biology, Université de Moncton, Moncton, NB, Canada. ${ }^{3}$ Endocannabinoids and NeuroAdaptation, NeuroCentre, INSERM U1215 Bordeaux, France. ${ }^{4}$ Université de Bordeaux, Bordeaux, France. ${ }^{5}$ Department of Chemistry and Biochemistry, Université de Moncton, Moncton, NB, Canada

\section{Conflict of interest}

The authors declare that they have no conflict of interest.

\section{Publisher's note}

Springer Nature remains neutral with regard to jurisdictional claims in published maps and institutional affiliations.

Supplementary Information accompanies this paper at (https://doi.org/ 10.1038/s41419-019-2134-8).

Received: 25 April 2019 Revised: 9 October 2019 Accepted: 6 November 2019

Published online: 09 December 2019

\section{References}

1. Aftimos, P., Azim, H. A. \& Sotiriou, C. Chapter 26 - Molecular Biology of Breast Cancer. in Molecular Pathology 2nd Edn (eds. Coleman, W. B. \& Tsongalis, G. J.) 569-588 (Academic Press, 2018). https://doi.org/10.1016/B978-0-12-802761$5.00026-2$

2. Wang, Y., Cao, S. \& Chen, Y. Molecular treatment of different breast cancers. Anticancer Agents Med. Chem. 15, 701-720 (2015).

3. Godone, R. L. N. et al. Clinical and molecular aspects of breast cancer: targets and therapies. Biomed. Pharmacother. Biomedecine Pharmacother. 106, 14-34 (2018).

4. Heiden, M. G. V., Cantley, L. C. \& Thompson, C. B. Understanding the Warburg effect: the metabolic requirements of cell proliferation. Science $\mathbf{3 2 4}$ 1029-1033 (2009).

5. Jose, C., Bellance, N. \& Rossignol, R. Choosing between glycolysis and oxidative phosphorylation: a tumor's dilemma? Biochim. Biophys. Acta BBA - Bioenerg. 1807, 552-561 (2011).

6. Ma, Y., Bai, R.-K., Trieu, R. \& Wong, L.-J. C. Mitochondrial dysfunction in human breast cancer cells and their transmitochondrial cybrids. Biochim. Biophys. Acta BBA - Bioenerg. 1797, 29-37 (2010).

7. Pelicano, $\mathrm{H}$. et al. Mitochondrial dysfunction in some triple-negative breast cancer cell lines: role of mTOR pathway and therapeutic potential. Breast Cancer Res. 16, 434 (2014)

8. Sabharwal, S. S. \& Schumacker, P. T. Mitochondrial ROS in cancer: initiators, amplifiers or an Achilles' heel? Nat. Rev. Cancer 14, 709-721 (2014).

9. Ahn, C. S. \& Metallo, C. M. Mitochondria as biosynthetic factories for cancer proliferation. Cancer Metab. 3, 1 (2015).

10. Zhao, J. et al. Mitochondrial dynamics regulates migration and invasion of breast cancer cells. Oncogene 32, 4814-4824 (2013).
11. Gross, M. I. et al. Antitumor activity of the glutaminase inhibitor CB-839 in triple-negative breast cancer. Mol. Cancer Ther. 13, 890-901 (2014).

12. Yeatman, T. J. A renaissance for SRC. Nat. Rev. Cancer 4, 470-480 (2004).

13. Espada, J. \& Martín-Pérez, J. An update on Src family of nonreceptor tyrosine kinases biology. Int. Rev. Cell Mol. Biol. 331, 83-122 (2017).

14. Elsberger, B. et al. Breast cancer patients' clinical outcome measures are associated with Src kinase family member expression. Br. J. Cancer 103, 899-909 (2010).

15. Tan, M. et al. ErbB2 promotes Src synthesis and stability: novel mechanisms of Src activation that confer breast cancer metastasis. Cancer Res. 65, 1858-1867 (2005).

16. Verbeek, B. S. et al. c-Src protein expression is increased in human breast cancer. An immunohistochemical and biochemical analysis. J. Pathol. 180, 383-388 (1996)

17. Ma, J. et al. PH006, a novel and selective Src kinase inhibitor, suppresses human breast cancer growth and metastasis in vitro and in vivo. Breast Cancer Res. Treat. 130, 85-96 (2011).

18. Jallal, H. et al. A Src/Abl kinase inhibitor, SKI-606, blocks breast cancer invasion, growth, and metastasis in vitro and in vivo. Cancer Res. 67, 1580-1588 (2007).

19. Nautiyal, J., Majumder, P., Patel, B. B., Lee, F. Y. \& Majumdar, A. P. N. Src inhibitor dasatinib inhibits growth of breast cancer cells by modulating EGFR signaling. Cancer Lett. 283, 143-151 (2009).

20. Sánchez-Bailón, M. P. et al. Cyr61 as mediator of Src signaling in triple negative breast cancer cells. Oncotarget 6, 13520-13538 (2015).

21. Sánchez-Bailón, M. P. et al. Src kinases catalytic activity regulates proliferation, migration and invasiveness of MDA-MB-231 breast cancer cells. Cell. Signal. 24, 1276-1286 (2012).

22. Puls, L. N., Eadens, M. \& Messersmith, W. Current status of SRC inhibitors in solid tumor malignancies. Oncologist 16, 566-578 (2011).

23. Mayer, E. L. \& Krop, I. E. Advances in targeting SRC in the treatment of breast cancer and other solid malignancies. Clin. Cancer Res. J. Am. Assoc. Cancer Res. 16, 3526-3532 (2010)

24. Saad, F. \& Lipton, A. SRC kinase inhibition: targeting bone metastases and tumor growth in prostate and breast cancer. Cancer Treat. Rev. 36, 177-184 (2010).

25. Miyazaki, T., Neff, L., Tanaka, S., Horne, W. C. \& Baron, R. Regulation of cytochrome c oxidase activity by c-Src in osteoclasts. J. Cell Biol. 160, 709-718 (2003).

26. Hebert-Chatelain, E. et al. Preservation of NADH ubiquinone-oxidoreductase activity by Src kinase-mediated phosphorylation of NDUFB10. Biochim. Biophys. Acta 1817, 718-725 (2012).

27. Demory, M. L. et al. Epidermal growth factor receptor translocation to the mitochondria: regulation and effect. J. Biol. Chem. 284, 36592-36604 (2009).

28. Hébert Chatelain, E., Dupuy, J.-W., Letellier, T. \& Dachary-Prigent, J. Functional impact of PTP1B-mediated Src regulation on oxidative phosphorylation in rat brain mitochondria. Cell. Mol. Life Sci. CMLS 68, 2603-2613 (2011).

29. Ogura, M., Yamaki, J., Homma, M. K. \& Homma, Y. Mitochondrial c-Src regulates cell survival through phosphorylation of respiratory chain components. Biochem. J. 447, 281-289 (2012).

30. Hebert-Chatelain, E. Src kinases are important regulators of mitochondrial functions. Int. J. Biochem. Cell Biol. 45, 90-98 (2013).

31. Gottlieb-Abraham, E., Gutman, O., Pai, G. M., Rubio, I. \& Henis, Y. I. The residue at position 5 of the N-terminal region of Src and Fyn modulates their myristoylation, palmitoylation, and membrane interactions. Mol. Biol. Cell 27, 3926-3936 (2016).

32. Guedouari, H., Daigle, T., Scorrano, L. \& Hebert-Chatelain, E. Sirtuin 5 protects mitochondria from fragmentation and degradation during starvation. Biochim. Biophys. Acta 1864, 169-176 (2017).

33. Jose, C. et al. AICAR inhibits cancer cell growth and triggers cell-type distinct effects on OXPHOS biogenesis, oxidative stress and Akt activation. Biochim. Biophys. Acta 1807, 707-718 (2011).

34. Kim, K. H. \& Sederstrom, J. M. Assaying cell cycle status using flow cytometry. Curr. Protoc. Mol. Biol. 111, 28.6.1-11 (2015).

35. Navarro-Sastre, A. et al. Lethal hepatopathy and leukodystrophy caused by a novel mutation in MPV17 gene: description of an alternative MPV17 spliced form. Mol. Genet. Metab. 94, 234-239 (2008)

36. Quiros, P. M., Goyal, A., Jha, P. \& Auwerx, J. Analysis of mtDNA $/ n D N A$ ratio in mice. Curr. Protoc. Mouse Biol. 7, 47-54 (2017).

37. Stanley, A., Ashrafi, G. H., Seddon, A. M. \& Modjtahedi, H. Synergistic effects of various Her inhibitors in combination with IGF-1R, C-MET and Src targeting agents in breast cancer cell lines. Sci. Rep. 7, 3964 (2017). 
38. Garcia-Recio, S., Pastor-Arroyo, E. M., Marín-Aguilera, M., Almendro, V. \& Gascón, $P$. The transmodulation of HER2 and EGFR by substance $P$ in breast cancer cells requires C-Src and metalloproteinase activation. PLOS ONE 10, e0129661 (2015).

39. Marroquin, L. D., Hynes, J., Dykens, J. A., Jamieson, J. D. \& Will, Y. Circumventing the Crabtree effect: replacing media glucose with galactose increases susceptibility of HepG2 cells to mitochondrial toxicants. Toxicol. Sci. J. Soc. Toxicol. 97, 539-547 (2007).

40. Aguer, C. et al. Galactose enhances oxidative metabolism and reveals mitochondrial dysfunction in human primary muscle cells. PLOS ONE 6, e28536 (2011).

41. Melser, S. et al. Rheb regulates mitophagy induced by mitochondrial energetic status. Cell Metab. 17, 719-730 (2013).

42. Ciesielski, G. L. et al. Mitochondrial single-stranded DNA-binding proteins stimulate the activity of DNA polymerase $\gamma$ by organization of the template DNA. J. Biol. Chem. 290, 28697-28707 (2015).

43. Korhonen, J. A., Gaspari, M. \& Falkenberg, M. TWINKLE Has $5^{\prime} \rightarrow 3^{\prime}$ DNA helicase activity and is specifically stimulated by mitochondrial single-stranded DNA-binding protein. J. Biol. Chem. 278, 48627-48632 (2003).

44. Palacios-Moreno, J. et al. Neuroblastoma tyrosine kinase signaling networks involve FYN and LYN in endosomes and lipid rafts. PLoS Comput. Biol. 11, e1004130 (2015).

45. Tsai, C.-F. et al. Large-scale determination of absolute phosphorylation stoichiometries in human cells by motif-targeting quantitative proteomics. Nat. Commun. 6, 6622 (2015)

46. Johnson, H. \& White, F. M. Quantitative analysis of signaling networks across differentially embedded tumors highlights interpatient heterogeneity in human glioblastoma. J. Proteome Res. 13, 4581-4593 (2014).

47. Rolland, D. et al. Global phosphoproteomic profiling reveals distinct signatures in B-cell non-Hodgkin lymphomas. Am. J. Pathol. 184, 1331-1342 (2014).

48. Schweppe, D. K., Rigas, J. R. \& Gerber, S. A. Quantitative phosphoproteomic profiling of human non-small cell lung cancer tumors. J. Proteom. 91, 286-296 (2013).

49. Bai, $Y$. et al. Phosphoproteomics identifies driver tyrosine kinases in sarcoma cell lines and tumors. Cancer Res. 72, 2501-2511 (2012).

50. Hornbeck, P. V. et al. PhosphoSitePlus, 2014: mutations, PTMs and recalibrations. Nucleic Acids Res. 43, D512-D520 (2015).

51. Tseng, L.-M. et al. Mitochondrial DNA mutations and mitochondrial DNA depletion in breast cancer. Genes. Chromosomes Cancer 45, 629-638 (2006).

52. Copeland, W. C., Wachsman, J. T., Johnson, F. M., Penta, J. S. \& Mitochondrial, D. N. A. alterations in cancer. Cancer Invest. 20, 557-569 (2002).

53. Ruhanen, $H$. et al. Mitochondrial single-stranded DNA binding protein is required for maintenance of mitochondrial DNA and 7S DNA but is not required for mitochondrial nucleoid organisation. Biochim. Biophys. Acta BBA Mol. Cell Res. 1803, 931-939 (2010).

54. Shapovalov, Y., Hoffman, D., Zuch, D., de Mesy Bentley, K. L. \& Eliseev, R. A. Mitochondrial dysfunction in cancer cells due to aberrant mitochondrial replication. J. Biol. Chem. 286, 22331-22338 (2011).

55. Wang, $Y$. et al. Downregulation of mitochondrial single stranded DNA binding protein (SSBP1) Induces mitochondrial dysfunction and increases the radiosensitivity in non-small cell lung cancer cells. J. Cancer 8, 1400-1409 (2017).

56. Guha, M. et al. Aggressive triple negative breast cancers have unique molecular signature on the basis of mitochondrial genetic and functional defects. Biochim. Biophys. Acta Mol. Basis Dis. 1864, 1060-1071 (2018).

57. Jiang, H.-L. et al. SSBP1 suppresses TGFß-Driven epithelial-to-mesenchymal transition and metastasis in triple-negative breast cancer by regulating mitochondrial retrograde signaling. Cancer Res. 76, 952-964 (2016).

58. Chourasia, A. H. et al. Mitophagy defects arising from BNip3 loss promote mammary tumor progression to metastasis. EMBO Rep. 16, 1145-1163 (2015)

59. Guerra, F. et al. Mitochondrial dysfunction: a novel potential driver of epithelialto-mesenchymal transition in cancer. Front. Oncol. 7, 295 (2017).

60. Santidrian, A. F. et al. Mitochondrial complex I activity and $\mathrm{NAD}^{+} / \mathrm{NADH}$ balance regulate breast cancer progression. J. Clin. Invest. 123, 1068-1081 (2013).

61. Schell, J. C. et al. A role for the mitochondrial pyruvate carrier as a repressor of the Warburg effect and colon cancer cell growth. Mol. Cell 56, 400-413 (2014).

62. Li, Y. et al. Mitochondrial pyruvate carrier function is negatively linked to Warburg phenotype in vitro and malignant features in esophageal squamous cell carcinomas. Oncotarget 8, 1058-1073 (2016).

63. Tang, X.P. et al. Mitochondrial pyruvate carrier 1 functions as a tumor suppressor and predicts the prognosis of human renal cell carcinoma. Lab. Invest. 99, 191 (2019).

64. Jin, Y. et al. Src drives the Warburg effect and therapy resistance by inactivating pyruvate dehydrogenase through tyrosine-289 phosphorylation. Oncotarget 7, 25113-25124 (2016).

65. Feigin, M. E. et al. Mislocalization of the cell polarity protein scribble promotes mammary tumorigenesis and is associated with basal breast cancer. Cancer Res. 74, 3180-3194 (2014).

66. Zhan, L. et al. Deregulation of scribble promotes mammary tumorigenesis and reveals a role for cell polarity in carcinoma. Cell 135, 865-878 (2008).

67. Frasa, M. A. M. et al. Armus Is a Rac1 Effector that Inactivates Rab7 and Regulates E-Cadherin Degradation. Curr. Biol. 20, 198-208 (2010).

68. Deng, W. et al. MICAL1 controls cell invasive phenotype via regulating oxidative stress in breast cancer cells. BMC Cancer 16, 489 (2016).

69. Rikardsen, O. G. et al. Plectin as a prognostic marker in non-metastatic oral squamous cell carcinoma. BMC Oral. Health 15, 98 (2015).

70. Katada, K. et al. Plectin promotes migration and invasion of cancer cells and is a novel prognostic marker for head and neck squamous cell carcinoma. J. Proteom. 75, 1803-1815 (2012).

71. Ren, Y., Li, R., Zheng, Y. \& Busch, H. Cloning and characterization of GEF-H1, a microtubule-associated guanine nucleotide exchange factor for Rac and Rho GTPases. J. Biol. Chem. 273, 34954-34960 (1998).

72. Liao, Y. C. et al. Overexpressed hPTTG1 promotes breast cancer cell invasion and metastasis by regulating GEF-H1/RhoA signalling. Oncogene $\mathbf{3 1}$, 3086-3097 (2012).

73. Kim, T. Y. et al. Effects of structure of Rho GTPase-activating protein DLC-1 on cell morphology and migration. J. Biol. Chem. 283, 32762-32770 (2008). 